\title{
A 250 kW Four Quadrant Switch Mode Converter for the 1.4 GeV PS-Booster Beam Transfer Lines at CERN
}

\author{
S.Dewan (DPS), R.Holmes (IE), K.Reiniger (TRIUMF), \\ F.Voelker (CERN), J.Zeng (UOT)
}

\begin{abstract}
This paper describes a four quadrant, $250 \mathrm{~kW}(550 \mathrm{~V}$, 450A) switch-mode, zero current soft switching (ZCS) power converter for a $1.4 \mathrm{GeV}$ beam transfer line magnet. The ZCS technique is the preferred approach for the high power switch-mode converters employing Insolated Gate Bipolar Transistors (IGBT) to reduce switching losses and EMI. This switch-mode power converter topology has been selected because of the high dynamic response, low output ripple, and low input current harmonics. In this paper, the circuit topology, function of the system components, key system specifications and experimental results for a $250 \mathrm{~kW}$ switch-mode converter are described in detail. The experimental results include output current transient response and conducted electromagnetic interference (EMI, measurements at both AC input and DC output). The design and development process employed is based on virtual electrical simulation of the system. This technique has been essential for the successful development of this unit.
\end{abstract}

\section{INTRODUCTION}

This paper deals with the description, specification, experimental and simulation results of $250 \mathrm{~kW}$ switch mode converter for pulse magnet power supplies. In section 2, the basic converter topology including control philosophy and system parameters is described. The key specifications are outlined in section 3. The experimental results including input and output EMI are outlined in section 4. The simulation results and the prototype development process are discussed in section 5 .

\section{BASIC CONVERTER SYSTEM}

Figures 1 and 2 show the essential elements of the 250 $\mathrm{kW}$ four-quadrant switch mode converter system.

- EMI filter (EMI1) reduces conducted EMI to the input source.

- Reactors (Ls and Lp) and capacitor (Cp) provide required reduction of the input harmonic currents.

- Diodes (D1 to D6) convert three-phase AC voltage to DC voltage.

- Two stage LC filters (Lf1, Lf3, Cf1, Cf3), with a corner frequency of approximately $40 \mathrm{~Hz}$, reduce the line harmonic voltage from the converter output.

- Damping capacitor $(\mathrm{Cf} 2)$ and resistor $(\mathrm{Rd} 2)$ reduce dc voltage change during the step change in the input source voltage.
- Three $100 \mathrm{~kW}$ high power inverter modules are connected with the primaries of the three $18 \mathrm{kHz}$ isolation transformers (TR1A, TR1B, TR1C) in parallel and the secondaries in series. This configuration is extremely rugged and, the current sharing in the three modules is ensured by this circuit topology.

- Each high frequency inverter module consists of a high frequency filter (Lhf, Chf) that ensures that switching frequency currents generated by the inverter does not flow back to the line. IGBTs (S1 to S4) are connected in a full bridge configuration and switched at $18 \mathrm{kHz}$ to convert the DC to high frequency $(18 \mathrm{kHz}) \mathrm{AC}$.

- Diodes DO1 to DO4 rectify the high frequency AC to DC.

- Two stage output filters (Lo1, Co1, Lo2, Co2), with a corner frequency about $2 \mathrm{kHz}$, reduce the switching frequency voltage ripple in the output.

- Output damping capacitor (Co3) and resistor (Ro3) improve output transient performance for the pulsing applications.

- The control strategy for the high frequency inverter employs an outer magnet current $\left(\mathrm{I}_{\mathrm{o}}\right)$ loop with an inner unfiltered voltage $\left(\mathrm{V}_{\mathrm{r}}\right)$ loop.

- Figure 2 shows the basic four quadrant regenerative circuit and its connections with converter in figure 1. This circuit consists of; Isolation IGBT switch T5 for disconnecting from the high frequency converter, Isolating diode D5 and energy storage capacitor C5, SCR reversing switch Q1 to Q4, crowbar SCR (SC) to protect over-voltage on $\mathrm{C} 5$, output EMI filter (EMI2) to reduce conducted EMI in the magnet current. A regenerative three phase SCR bridge (T1 to T6) operating at a fixed delay angle of 150 degrees and the source isolation transformer TRG.

- Parameters for the $250 \mathrm{~kW}$ switch mode converter in figures 1 and 2 are:

$$
\begin{aligned}
& \mathrm{Vab}=400 \mathrm{~V}, \mathrm{Vo}=550 \mathrm{~V}, \mathrm{Io}=450 \mathrm{~A} \text {; } \\
& \mathrm{Ls}=190 \mu \mathrm{H}, \mathrm{Lp}=293 \mu \mathrm{H}, \mathrm{Cp}=460 \mu \mathrm{F} \text {; } \\
& \mathrm{Lf1}=\mathrm{Lf} 3=0.8 \mathrm{mH}, \mathrm{Cf1}=\mathrm{Cf} 3=30,000 \mu \mathrm{F} \text {; } \\
& \mathrm{Cf} 2=90,000 \mu \mathrm{F}, \mathrm{Rd} 2=0.365 \Omega \text {; } \\
& \mathrm{Lhf}=10 \mu \mathrm{H}, \mathrm{Chf}=40 \mu \mathrm{F} \text {; } \\
& \text { Turn Ratio of TR1, TR2, \& TR3 } \mathrm{N}=0.5 \text {; } \\
& \mathrm{Lo} 1=\mathrm{Lo} 2=100 \mu \mathrm{H}, \mathrm{Co} 1=100 \mu \mathrm{F}, \mathrm{Co} 2=60 \mu \mathrm{F} \text {; } \\
& \mathrm{Co} 3=500 \mu \mathrm{F}, \mathrm{Ro} 3=0.28 \Omega \text {; } \\
& \text { Voltage ratio of TRG is } 1.25, \mathrm{C} 5=60,000 \mu \mathrm{F} \text {. }
\end{aligned}
$$




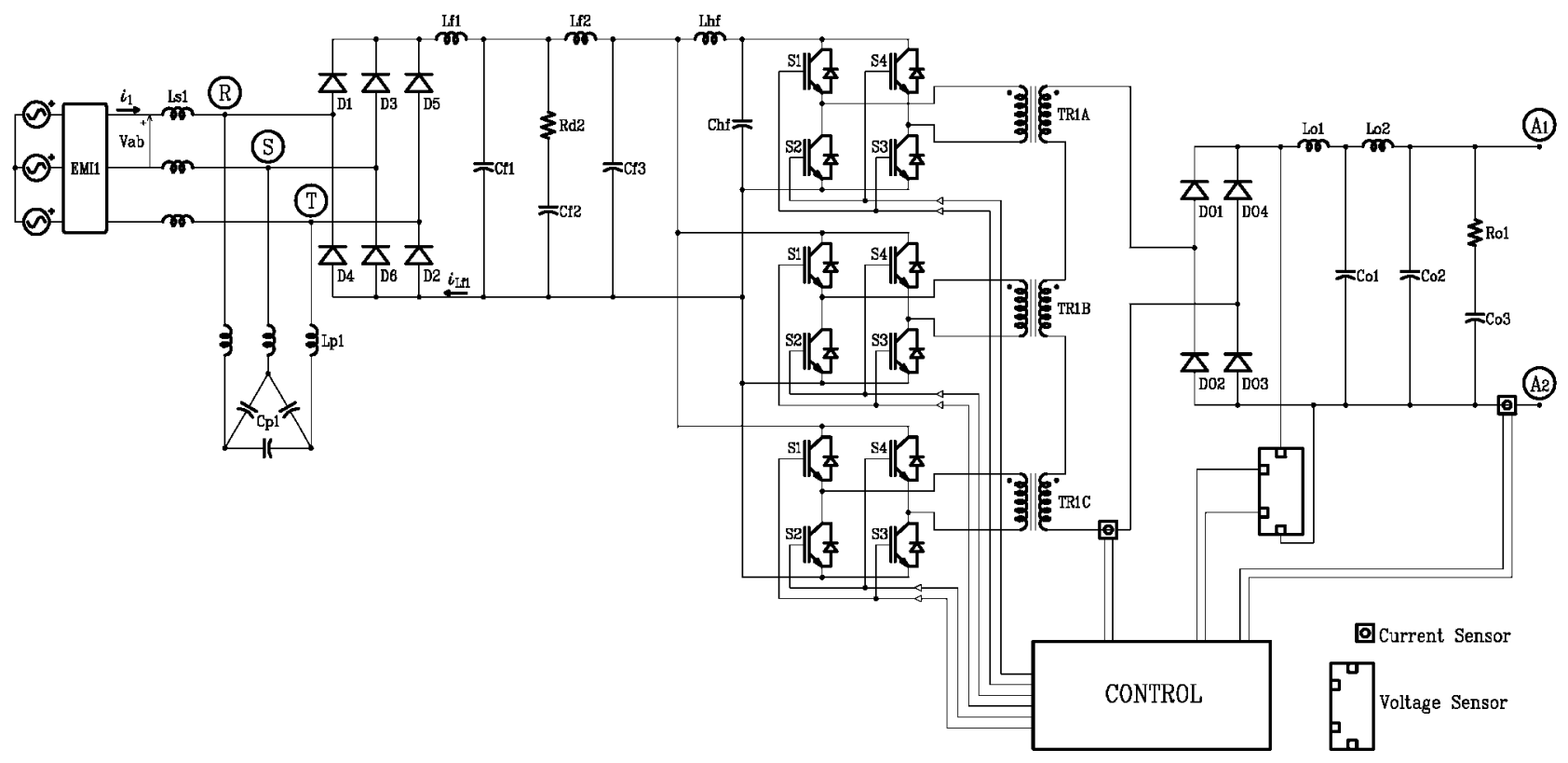

Figure 1: Basic 250 kW Switch Mode Converter System as Input to Four Quadrant Regeneration- Circuit (Fig.2)

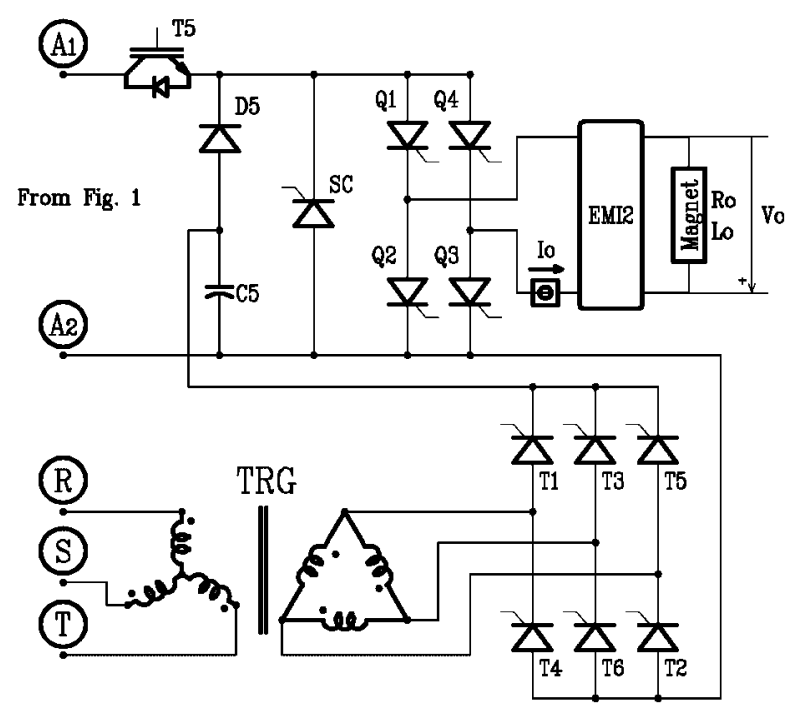

Figure 2: Basic Four Quadrant Regenerative Circuit with $250 \mathrm{~kW}$ Converter in Figure 1

\section{KEY SYSTEM SPECIFICATIONS}

This section identifies the significant performance requirements/results for input and output of the $250 \mathrm{~kW}$ converter. Both simulation and experiments have verified that the required performance has been met.

\subsection{Input}

Voltage RMS

Current RMS

Current Harmonic

Distortion

Efficiency at Full Load

Efficiency at $50 \%$ Load

EMI

$$
\begin{gathered}
400 \mathrm{~V} \pm 10 \% \\
410 \mathrm{~A} \\
<21 \mathrm{~A}(5 \%) \\
>95 \% \\
>90 \%
\end{gathered}
$$

EN-5501/Gr-1CI-A, VDE-08715 Grade N

\subsection{Output}

DC Voltage, Continuous DC Current, Continuous

Unfiltered Voltage Loop

Bandwidth

Closed Current Loop

Bandwidth

Low Frequency Output

Voltage Ripple up to $1 \mathrm{kHz}$

High Frequency Output

Voltage Ripple greater than 1

$\mathrm{kHz}$

Dynamic Response in

Current Mode with Magnet

$\mathrm{R}=0.42 \Omega, \mathrm{L}=370 \mathrm{mH}$ (Time constant $925 \mathrm{~ms}$ )

$$
\begin{aligned}
& 0 \text { to } 550 \mathrm{~V} \\
& 0 \text { to } 450 \mathrm{~A} \\
& >2,000 \mathrm{~Hz} \\
& >300 \mathrm{~Hz} \\
& <100 \mathrm{mV}_{\text {P-P }} \\
& <200 \mathrm{mV}_{\text {P-P }}
\end{aligned}
$$

Settling time to $100 \mathrm{ppm}$ of rated current within 750 $\mathrm{ms}$ for modulation of $+100 \%$ to $-100 \%$ 


\section{EXPERIMENTAL RESULTS}

Input line current and output voltage ripple (low and high frequency) results are similar to the results presented in $100 \mathrm{~kW}$ paper [1]. Tables 1 and 2 show EMI results at input and output of the unit, respectively. Figures 3 and 4 show the waveforms at full power for magnet voltage (Vo) magnet current (Io) and energy storage capacitor C5 voltage (V5) during rise, flat and fall periods of the magnet current. Figure 5 shows the magnet voltage and current waveforms during reversal of magnet current from $+100 \%$ to $-100 \%$.

Table 1: Worst Case Input EMI Test Data of 250kW Four Quadrant Switch Mode Converter

\begin{tabular}{|c|c|c|c|c|c|}
\hline $\begin{array}{c}\text { Freq } \\
(\mathrm{MHz})\end{array}$ & $\begin{array}{c}\text { RF } \\
\text { Level } \\
(\mathrm{dBuV})\end{array}$ & $\begin{array}{c}\text { Receiver } \\
\text { Detector } \\
(\mathrm{P} / \mathrm{QP} / \mathrm{AVG})\end{array}$ & $\begin{array}{c}\text { QP } \\
\text { Limit } \\
(\mathrm{dBuV})\end{array}$ & $\begin{array}{c}\text { AVG } \\
\text { Limit } \\
(\mathrm{dBuV})\end{array}$ & $\begin{array}{c}\text { Margin } \\
(\mathrm{dB})\end{array}$ \\
\hline 0.20 & 56.2 & QP & 79.0 & 66.0 & -22.8 \\
\hline 0.20 & 56.2 & AVG & 79.0 & 66.0 & -9.8 \\
\hline 0.75 & 46.4 & QP & 73.0 & 60.0 & -26.6 \\
\hline 0.75 & 46.3 & AVG & 73.0 & 60.0 & -13.7 \\
\hline 0.86 & 48.8 & QP & 73.0 & 60.0 & -24.2 \\
\hline 0.86 & 46.6 & AVG & 73.0 & 60.0 & -13.4 \\
\hline 1.05 & 55.5 & QP & 73.0 & 60.0 & -17.5 \\
\hline 1.05 & 55.5 & AVG & 73.0 & 60.0 & -4.5 \\
\hline 2.75 & 41.1 & QP & 73.0 & 60.0 & -31.9 \\
\hline 2.75 & 39.4 & AVG & 73.0 & 60.0 & -20.6 \\
\hline 5.23 & 50.5 & QP & 73.0 & 60.0 & -22.5 \\
\hline 5.23 & 49.4 & AVG & 73.0 & 60.0 & -23.6 \\
\hline \multicolumn{7}{|c}{}
\end{tabular}

Table 2: Worst Case Output EMI Test Data of 250kW Four Quadrant Switch Mode Converter

\begin{tabular}{|c|c|c|c|c|c|c|}
\hline $\begin{array}{c}\text { Freq } \\
(\mathrm{MHz})\end{array}$ & 0.408 & 0.497 & 0.904 & 1.083 & 5.25 & 10.96 \\
\hline $\begin{array}{c}\text { RF Level } \\
(\mathrm{dBuV})\end{array}$ & 87.8 & 89.8 & 90.7 & 63.1 & 87.6 & 63.1 \\
\hline
\end{tabular}

Note: The emissions were scanned from $150 \mathrm{kHz}$ to 30 $\mathrm{MHz}$ at AC mains via a LISN.

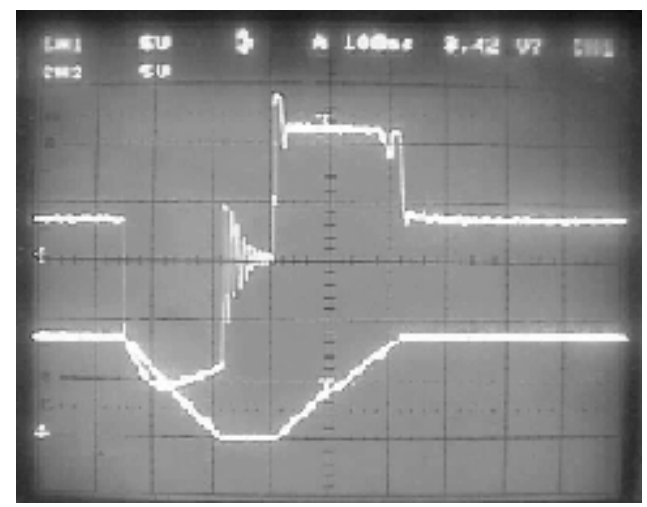

Figure 3: Magnet Voltage,Vo (275V/div, $100 \mathrm{~ms} / \mathrm{div})$ and Magnet Current, Io (250A/div, 100ms/div)

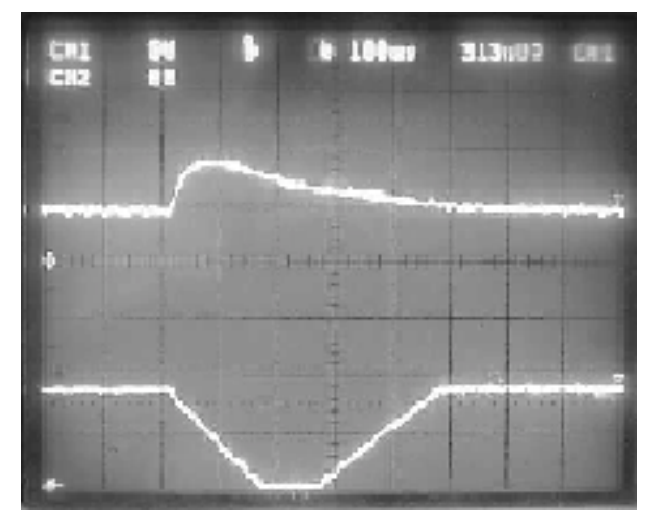

Figure 4: Energy Storage Voltage, V5 (330V/div) and Magnet Current, Io (250A/div, 100ms/div)

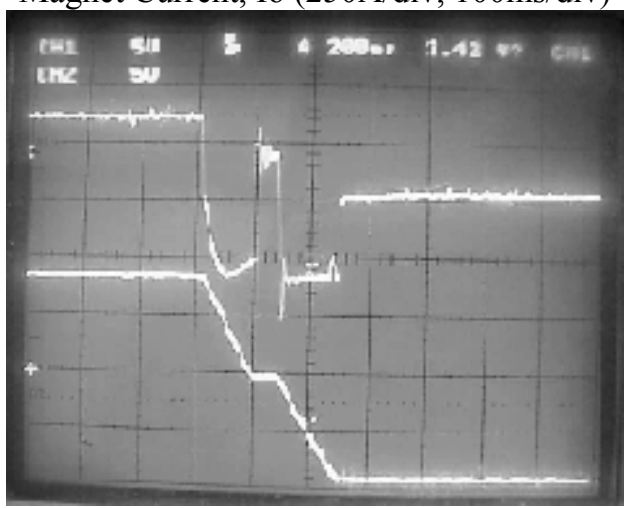

Figure 5: Magnet Voltage, Vo(275V/div, 200ms/div) and Magnet Current, Io (250A/div, 200ms/div)

\section{SIMULATION RESULTS}

This virtual electrical prototyping by simulation has been extremely useful in the reduction of design and implementation periods for the prototype. The simulation results for all the relevant performance, including system losses and EMI were close to the experimental results.

\section{CONCLUSIONS}

This paper has discussed the features and results of a $250 \mathrm{~kW}$ four-quadrant switch mode converter. This converter was designed and tested using a virtual prototyping simulation process described in [1]. For any questions, please contact:

Shashi Dewan (sdewan@inverpower.com) or

Bob Holmes (iepower@iepower.com).

\section{REFERENCES}

[1] S.Dewan et. al "High Power Switch-mode Power Converters for the $1.4 \mathrm{GeV}$ PS-Booster Beam Transfer Lines at CERN", EPAC'2000, Vienna, June 2000 . 